\title{
Kratom Dependence: a Case report
}

\author{
CL Lai, AYK Wu
}

Chi-Lun Lai, Department of Psychiatry, Pamela Youde Nethersole Eastern Hospital, Hong Kong

Anna YK Wu, Department of Psychiatry, Pamela Youde Nethersole Eastern Hospital, Hong Kong

Address for correspondence: Dr Chi-Lun Lai, Department of Psychiatry, Pamela Youde Nethersole Eastern Hospital, 3 Lok Man Road, Chai Wan, Hong Kong.

Email:dr.laichilun@gmail.com

Submitted: 21 May 2020; Accepted: 30 April 2021

\section{Case presentation}

In April 2019, a 30-year-old unemployed man was admitted to the emergency department of Pamela Youde Nethersole Eastern Hospital for a suicidal attempt by overdosing various medications (including benzodiazepines, sleeping pills, and anti-depressant) secondary to kratom withdrawal symptoms including restlessness, myalgia, rhinorrhoea, and diarrhoea.

Since teenage, the patient had experienced intense social anxiety, worried about being the centre of attention, and avoided social interaction. After graduating with an associate degree, he worked as a librarian to minimise interactions with people but quit months later owing to the fear of people making enquiries. He lived with his family and idled at home for years. In his mid-20s, he started buying kratom through the Internet for self-medication to relieve social anxiety. Initially, he consumed about $3 \mathrm{~g}$ of powdered kratom per day, dissolved into water for drinking, and experienced relief of anxiety. Later, he developed tolerance and gradually increased the daily consumption up to $50 \mathrm{~g}$. Attempts to reduce consumption had been made, but the emergence of withdrawal symptoms (anxiety, myalgia, diarrhoea, and yawning) prompted him to continue consumption.

In June 2017, his family arranged for him to receive a course of detoxification in a psychiatric hospital in mainland China. He was discharged 1 month later with escitalopram $10 \mathrm{mg}$ daily, bupropion $150 \mathrm{mg}$ daily, clonazepam $3 \mathrm{mg}$ at bedtime, and zolpidem $10 \mathrm{mg}$ at bedtime. However, he started consuming kratom again after a short period of abstinence, as he considered that kratom had a better effect on social anxiety. His family tried to cut off financial support to him.

Upon admission to our hospital, physical examination and blood tests for levels of urea and electrolytes and functions of liver and thyroid showed normal results. Urine drug screening showed citalopram, zopiclone, zolpidem, and diazepam metabolites. Liquid chromatography-mass spectrometry was specially requested and it detected mitragynine in the same urine sample. The patient was diagnosed with social phobia and kratom dependence. Symptomatic treatment (with diazepam, paracetamol, and loperamide) for withdrawal symptoms was offered, but the patient requested a transfer to psychiatric hospital in China after a short stay.

The patient complied poorly with psychiatric followup examinations at our hospital. He remained idle at home with a chaotic lifestyle. He continued to use kratom and self-adjusted psychiatric medication such as addition of benzodiazepine and hypnotics. He started to use cough mixture to help quit kratom. He gradually developed dependence of cough mixtures, with complication of acute retention of urine that necessitated emergency treatment.

One year after first admission to our hospital, the patient was admitted again with a suicidal attempt secondary to intense withdrawal symptoms. He received a course of detoxification along with psychological intervention. He was discharged after 1 month of hospital stay.

\section{Discussion}

Mitragynia speciosa, commonly known as kratom, is a herb related to the coffee tree family, Rubiaceae. ${ }^{1}$ It is traditionally used by people in Southeast Asian countries for fatigue, pain control, cough, diarrhoea, and opioid withdrawal..$^{2-4}$ Kratom is sold in the forms of raw or chopped leaves, powder, gum, capsules, and tablets for tea brewing, chewing, oral ingestion, and inhalation by smoking. ${ }^{1,4,5}$ The most abundant biologically active alkaloid in kratom is mitragynine (66\%), followed by paynantheine, speciogynine, 7-hydroxymitragynine, speciophylline, and 20 other alkaloids. ${ }^{1,2,46}$ Mitragynine and 7-hydroxymitragynine are agonists of $\mu$ - and $\delta$-opioid receptors, causing opioid-like activity. ${ }^{1,3,4}$ Although 7-hydroxymitragynine accounts for only $2 \%$ of the total alkaloid content, it is significantly more potent than mitragynine. ${ }^{1,7}$ In animal studies, mitragynine stimulates the postsynaptic $\alpha-2$ adrenergic receptor and blocks stimulation of the serotonergic $5-\mathrm{HT}_{2 \mathrm{~A}}$ receptors, contributing to stimulant activities. $3,5,8$

Depending on the strain and dosage, kratom can produce opioid or stimulant-like effects..$^{3,6,8}$ Proportional differences in the active alkaloid in different strains of kratom provide different relative strengths of stimulant and opioid effects. ${ }^{3}$ Plants with white and green veins indigenous to Malaysia have more stimulating and mood-enhancing effects, whereas plants with red veins from Bali have a more analgesic effect. ${ }^{3}$ At a low-to-moderate dose (1-5 g of raw leaves), kratom has a mild stimulant effect along with reduced fatigability, increased alertness, sociability, and sexual desire. ${ }^{3,6,8}$ Anxiety and internal agitation are common adverse effects. At a dose of 5-15 g of raw leaves, the opioid 
effect emerges, with analgesic effect and slight euphoria. ${ }^{3,6,8}$ At higher doses, users may experience sweating, dizziness, nausea, and dysphoria, followed by calmness, euphoria, and a dreamlike state. ${ }^{3,8}$ Psychotic symptoms after kratom use are infrequent (4\%). ${ }^{9}$

Prolonged use of kratom can lead to dependence. ${ }^{1,4,8}$ Chronic high-dose users may experience withdrawal symptoms such as nausea, insomnia, yawning, rhinorrhoea, myalgia, diarrhoea, and arthralgia mimicking opioid withdrawal., ${ }^{3,46}$ Although withdrawal symptoms are generally mild even for heavy users, ${ }^{3}$ they were severe and distressing in our patient. Animal studies have suggested chronic exposure to kratom could impair working memory and memory consolidation. ${ }^{4}$ However, impairment of cognitive functions such as motor, memory attention, and executive function has not been observed in humans. ${ }^{10}$ Other adverse effects include liver toxicity, hypothyroidism, and seizure. 1,3,4 $^{3}$ Mortality related to kratom has been reported $^{11}$ but mostly associated with concurrent use of other drugs. ${ }^{3}$

Owing to similar pharmacodynamic properties of kratom and opioid, treatment strategy for opioid misuse is recommended for kratom misuse.,12 Benzodiazepine, antihistamine, antiemetics, antidiarrheal, laxative, and analgesics are prescribed for symptomatic relief in kratom withdrawal. ${ }^{1,12}$ For acute intoxication, naloxone, an antagonist of opioid receptors, is used for reversal of the opioid effect. ${ }^{12}$ Buprenorphine-naloxone is used for maintenance treatment. ${ }^{12}$ In addition, psychosocial intervention is important for long-term abstinence.

The legal status of kratom differs among countries. It is listed as a controlled substance in Denmark, Sweden, Singapore, Australia, and New Zealand, ${ }^{3,8}$ but it is not controlled and listed as a 'drugs and chemicals of concern' by the United States Drug Enforcement Administration. ${ }^{13}$ In Hong Kong, kratom is not a controlled substance under the Dangerous Drugs Ordinance or the Pharmacy and Poisons Ordinance; therefore, its use and possession are not regulated. Kratom is easily accessible online and offline, with a cost of $\mathrm{HK} \$ 150$ for $50 \mathrm{~g} .{ }^{14}$ Kratom is an emerging substance with abuse potential, higher public awareness is warranted. Laboratories of Hospital Authority should consider testing kratom's active alkaloids (Mitragynine and 7-hydroxymitragynine) in urine drug screening to monitor the trend of kratom use.

\section{Declaration}

The authors have no conflict of interest to disclose.

\section{References}

1. White CM. Pharmacologic and clinical assessment of kratom. Am J Health Syst Pharm 2018;75:261-7. Crossref

2. Le D, Goggin MM, Janis GC. Analysis of mitragynine and metabolites in human urine for detecting the use of the psychoactive plant kratom. J Anal Toxicol 2012;36:616-25. Crossref

3. Warner ML, Kaufman NC, Grundmann O. The pharmacology and toxicology of kratom: from traditional herb to drug of abuse. Int $\mathbf{J}$ Legal Med 2016;130:127-38. Crossref

4. Hassan Z, Muzaimi M, Navaratnam V, Yusoff NH, Suhaimi FW, Vadivelu R, et al. From Kratom to mitragynine and its derivatives: physiological and behavioural effects related to use, abuse, and addiction. Neurosci Biobehav Rev 2013;37:138-51. Crossref

5. Rosenbaum CD, Carreiro SP, Babu KM. Here today, gone tomorrow... and back again? A review of herbal marijuana alternatives (K2, Spice), synthetic cathinones (bath salts), kratom, salvia divinorum, methoxetamine, and piperazines. J Med Toxicol 2012;8:15-32. Crossref

6. Prozialeck WC, Jivan JK, Andurkar SV. Pharmacology of kratom: an emerging botanical agent with stimulant, analgesic and opioid-like effects. J Am Osteopath Assoc 2012;112:792-9.

7. Takayama H. Chemistry and pharmacology of analgesic indole alkaloids from the rubiaceous plant, mitragyna speciosa. Chem Pharm Bull (Tokyo) 2004;52:916-28. Crossref

8. Kratom drug profile. The European Monitoring Centre for Drugs and Drug Addiction. http://www.emcdda.europa.eu/publications/drugprofiles/kratom_en\#. Accessed 5 May 2020.

9. Leong Bin Abdullah MFI, Singh D, Swogger MT, Rahim AA, Vicknasingam B. The prevalence of psychotic symptoms in kratom (Mitragyna speciosa Korth). Users in Malaysia. Asian J Psychiatr 2019;43:197-201. Crossref

10. Singh D, Narayanan S, Müller CP, Vicknasingam B, Yücel M, Ho ETW, et al. Long-term cognitive effects of kratom (Mitragyna speciosa Korth) use. J Psychoactive Drugs 2019;51:19-27. Crossref

11. Corkery JM, Streete P, Claridge H, Goodair C, Papanti D, Orsolini L, et al. Characteristics of deaths associated with kratom use. J Psychopharmacol 2019;33:1102-23. Crossref

12. Diep J, Chin DT, Gupta S, Syed F, Xiong M, Cheng J. Kratom, an emerging drug of abuse: a case report of overdose and management of withdrawal. A A Pract 2018;10:192-4. Crossref

13. Drugs of Abuse. Drug Enforcement Administration, U.S. Department of Justice. https://www.dea.gov/sites/default/files/ sites/getsmartaboutdrugs.com/files/publications/DoA_2017Ed_ Updated_6.16.17.pdf\#page $=84$ Accessed 5 May 2020.

14. Mok D. Hong Kong Lawmakers Call for Controls on Kratom, the Supplement Known as 'Legal Heroin.' This week in Asia, South China Morning Post; 2020. https://www.scmp.com/week-asia/healthenvironment/article/3075147/hong-kong-lawmakers-call-controlskratom-supplement Accessed 5 May 2020. 